\title{
A NECROPOLÍTICA DE ESTADO E O RACISMO ANTINEGRO: UMA ANÁLISE DISCURSIVA DO ASSASSINATO DE GEORGE FLOYD
}

\section{ARTIGO ORIGINAL}

SILVA, Evanildo Alves da ${ }^{1}$, BONFIM, Marco Antônio Lima do ${ }^{2}$

SILVA, Evanildo Alves da. BONFIM, Marco Antônio Lima do. A necropolítica de Estado e o racismo antinegro: uma análise discursiva do assassinato de George Floyd. Revista Científica Multidisciplinar Núcleo do Conhecimento. Ano 06, Ed. 12, Vol. 11, pp. 48-65. Dezembro de 2021. ISSN: 2448-0959, Link de acesso: https://www.nucleodoconhecimento.com.br/educacao/a-necropolitica

\section{RESUMO}

Neste artigo, temos o objetivo de tratar sobre o problema do racismo nos Estados Unidos, que vitimou George Floyd no dia 25 de maio de 2020, sendo assassinado pela polícia americana. Esse fato, alimentado pela estrutura do sistema do biopoder e da biopolítica, desagua na violência policial e resulta na seleção de quem deve viver e de quem deve morrer, desenlaçando o genocídio resultante da necropolítica de estado. Para isto, realizamos apontamentos sobre o percurso histórico da criação e do desenvolvimento dos Estados Unidos da América, com sua linha de divisão geográfica e geopolítica, abordando os conceitos de branqueamento, raça, racismo e o mito da democracia racial. Apoiamo-nos na fundamentação teórica de autores que tratam da história do povo negro e do enfrentamento ao racismo, tais como: Almeida (2018), Fernandes (2007), Mbembe (2017), Flores (2017), Nascimento (2019), Carnal (2007)

1 Mestrando em educação, especialização em filosofia do ensino médio, especialização em sociologia, especialização em políticas públicas e socioeducação, graduação em pedagogia.

2 Orientador. Pós-doutor em Educação e Ensino (PNPD/CAPES/MAIE/UECE). Doutor (2016) e mestre (2011) em Linguística Aplicada pelo Programa de Pós-Graduação em Linguística Aplicada da Universidade Estadual do Ceará (PosLA/UECE). 
e Munanga, (2008). A história do negro é assinalada por relações de dominação, de negação do direito à voz e à de liberdade de expressão, e pelo distanciamento social. Nesse sentido, indagamos: Quais instrumentos são indispensáveis para fomentar políticas de igualdade racial de forma satisfatória? Nessa perspectiva, encaminhamos pressupostos relativos a políticas de ações afirmativas que podem ser adotadas, no sentido de contribuir para a diminuição das desigualdades raciais, de maneira que os grupos elitizados, formados majoritariamente por brancos, não se mantenham predominando sobre os negros.

Palavras-chaves: racismo, negro, antirracismo, desigualdade, direito.

\section{INTRODUÇÃO}

O presente trabalho é fruto de leituras realizadas sobre racismo, discriminação e exclusão social, atiçado também pelos acontecimentos envolvendo o episódio que vitimou o norte americano George Floyd, ato cometido por um policial branco, que passou mais de oito minutos com o joelho sobre seu pescoço, causando sua morte por asfixia. Mesmo ele implorando por sua vida e repedindo a frase "eu não consigo respirar" por diversas vezes, não foi atendido. Os Estados Unidos são um país que se destaca por sua espetaculosa economia e cultura cinematográfica, onde afloram grandes personagens mundiais, a ponto de despertar em muitas pessoas, de diversas partes do mundo, o desejo de imigrarem para lá, na expectativa de firmar uma vida cercada de paz, alegria e prosperidade. Esse mesmo país, no entanto, provoca em tantos outros o sentimento de ódio, a ponto de cometerem ataques de guerrilha contra o povo estadunidense. Além dessas investidas desrespeitosas de outros países, pesa historicamente as porfias existentes, dentro do próprio país, entre negros e brancos que formam a nação.

Segundo Rocha (2020), a luta dos ativistas negros, que tiveram como seus precursores e arautos Martin Luther King e Malcolm X, permanece sendo travadas entre as sociedades atuais, por outros personagens e por outros contextos. $\mathrm{O}$ autor prossegue dizendo que "é triste", mas as discriminações em relação aos negros continuam sendo executadas ao longo da história. Esses fatos lamentáveis e 
inaceitáveis apenas mudam de nome, porém a discriminação, a intolerância e a marginalização dos negros, sobretudo entre os mais pobres, com a ausência de políticas públicas que garantam os direitos sociais recomendados pelos direitos humanos, continuam (ROCHA, 2020).

uso da força é adotado pelo Estado com a finalidade de manter sua estrutura de controle social. Ocorre que, por muitas vezes, as ações que são utilizadas para garantir a política de segurança nacional de um país são verdadeiras práticas de autoritarismo governamental, visando regulamentar a vida de determinado grupo de indivíduos. A utilização desse dispositivo é denominada de "biopolítica" por Michel Foucault (FLORES, 2017). E, para que o Estado tenha condição de colocar em prática a sua estrutura política governamental, ele se apropria de dispositivos tecnológicos e institucionais para controlar as ações da vida das pessoas, o que Michel Foucault denominou de "biopoder" (FLORES, 2017).

Flores (2017), citando Foucault, diz que o instrumento mais utilizado pelo Estado para tornar essas práticas aceitáveis e conseguir fiscalizar as pessoas é o discurso, que intenciona colar uma verdade em relação às formas de vida. Após realizada a análise das formas de vida, a biopolítica se utiliza do dispositivo do biopoder para decidir quais membros da sociedade podem viver e quais devem morrer. Nesse sentido, a vida se tornou um artefato controlado pelo saber, o qual se constitui sobre ela como objeto de controle social. Mbembe (2018) diz que o "racismo é acima de tudo uma tecnologia destinada a permitir o exercício do biopoder, este velho direito soberano de matar" (MBEMBE, 2018, p. 18).

No bojo da discussão feita por Michel Foucault, o historiador camaronês Mbembe apresenta o conceito de "necropolítica", que se constitui nos processos de colonização e neocolonização. Mbembe entende que o sistema escravocrata de plantio nas colônias se apresenta como uma forma de fronteira que desumaniza o humano, isto porque "as colônias são semelhantes às fronteiras. Elas são habitadas por 'selvagens'. As colônias não são organizadas de forma estatal e não criaram um mundo humano" (MBEMBE, 2017, p. 35). Nessas colônias, "o soberano tem a prerrogativa de matar sem qualquer objeção da lei” (MBEMBE, 2018, p. 36). Na 
análise de Mbembe, aquele modelo de genocídio praticado nas colônias foi transmutado para as sociedades atuais e urbanas. "Viver sob a ocupação contemporânea é experimentar uma condição permanente de 'viver na dor': estruturas fortificadas, postos militares e bloqueios de estradas em todo lugar" (MBEMBE, 2018, p. 68). A vigilância que se impõe sobre a sociedade moderna configura um protótipo de poder dominador, com "soldados patrulhando as ruas escuras, assustados pelas próprias sombras; crianças cegadas por balas de borracha; pais humilhados e espancados na frente de suas famílias" (MBEMBE, 2018, p. 69).

No dizer de Flores (2017), a necropolítica, nesse sentido, "simboliza o processo no qual o ser humano transforma-se em coisa útil ao Estado e ao sistema capitalista para estar viva ou não lhe serve de mais nada, podendo então ser dispensada" (FLORES, 2017, p. 44). É possível perceber, nesse cenário nebuloso, quem deve ser criminalizado e executado, sendo extinto do seio da sociedade, e geralmente é a pessoa negra e periférica que está em situação de maior vulnerabilidade social e/ou econômica. Assim, o povo negro enfrenta um processo de exclusão por ser considerado de risco para a sociedade. A necropolítica é sustentada pela característica de reprovar, reprimir e exterminar, sendo operada pelos polos da vida ou da morte. Por isto, tem a capacidade de se multiplicar de maneira espantosa, quer seja na morte de pessoas individualmente, quer na morte do genocídio de massa (MBEMBE, 2017, p. 65).

\section{O LUGAR DO NEGRO NA HISTÓRIA AMERICANA: AVANÇOS E REVERSOS}

A sociedade está sempre em processo mudanças sociais, políticas, econômicas e de identidades culturais. De acordo com Hall (2006), as identidades culturais sofrem constantes transformações, afastando-se indubitavelmente das velhas configurações de identidade que, por tanto tempo, se constituíram como identidades unificadas e tinham como objetivo eternizar o sistema de representação cultural absolvida da sociedade medieval. Hall demonstra que não é possível existir somente uma identidade cultural, em consequência da diversidade de culturas existentes na mesma 
nação, englobando gênero, etnia e raça (HALL, 2006). "As identidades nacionais não são coisas com as quais nós nascemos, mas são formadas e transformadas no interior da representação" (HALL, 2006, p. 48).

Os processos de constituição hegemônica de uma cultura unificada, desse modo, ocorrem por meio de processos violentos que tentam minguar e, consequentemente, eliminar as tentativas de aceitar as diversas e diferentes identidades culturas. No dizer de Hall, "cada conquista subjugou povos conquistados e suas culturas, costumes, línguas, tradições, e tentou impor uma hegemonia cultural mais unificada" (HALL, 2006, p. 60). Isto implica dizer que as nações, cada uma a seu modo, procuram homogeneizar a sua identidade nacional, com a finalidade de solidificar a sua estrutura de poder. Rodrigues (2021), descrevendo as palavras de Erica Malunguinho, diz que "o grande centro dos conflitos humanitários mundiais é tratar o colonialismo é como uma ferida estrutural do passado e que, portanto, não precisa ser revista contemporaneamente. Sendo assim, o colonialismo é uma ferida não tratada, dolorosa, por vezes infecciosa e que sangra." (RODRIGUES, 2021, P. 41).

Os Estados Unidos (espaço geopolítico deste artigo) não foram diferentes ao procurar construir e concretizar uma identidade nacional a partir de referências étnico-raciais predominantemente de pessoas brancas. Nessas circunstâncias, o negro foi espoliado e considerado a principal vergonha nacional, tornando-se uma ameaça ao novo modelo de sociedade que emergia no cenário nacional. A chave para a resolubilidade dessa problemática estava no alvitramento de uma proposta eugenista com a intenção de classificar biologicamente o branqueamento de uma única raça. $O$ que se desejou foi a busca de uma nação predominantemente branca, e, consequentemente, a inferiorização da população negra (NASCIMENTO, 1978).

O historiador Leandro Carnal (2007) faz um apanhado histórico desde o início da formação dos Estados Unidos, da criação das treze colônias originárias da Inglaterra até o início do século XXI. O autor relata que as colônias que foram fundadas ali já se estabeleceram sobre o mastro das diferenças econômicas e raciais. Enquanto, no norte do país, se assentou uma população predominantemente branqueada numa terra considerada fértil e abundante, o que possibilitou o desenvolvimento de grandes 
indústrias, do trabalho livre e da aquisição de pequenas propriedades de terras; Do outro lado, na região sul, se estabeleceu uma população predominantemente oriunda do trabalho escravo. O meio de sobrevivência encontrado pelos novos moradores da terra foi a aquisição de grandes propriedades de terra e o trabalho de monocultura. Com essa formação estrutural de economia, o uso do trabalho escravo se estabeleceu, mais especificamente o trabalho de escravos negros oriundos do continente africano (CARNAL, 2007).

Conforme Carnal (2007), o país enfrentou, de 1861 a 1865, a chamada Guerra Civil Americana, que aconteceu entre os estados do norte e os autoproclamados Estados Confederados da América. Os vencedores da batalha foram as colônias do norte, que, após conseguirem obter a vitória, ordenaram a imediata abolição da escravatura existente no território sulista. Com o fim da guerra, começaram as negociações para a reconstrução do país e, consequentemente, a reintegração dos estados do sul ao restante da nação. Muitos cidadãos brancos que habitavam na região sulista, entretanto, não concordaram que os negros, que tinham acabado de receber a liberdade, tivessem os mesmos direitos que os brancos. Esse é o início das primeiras tentativas de uma política segregacionista que se arrastou por muitos anos. Sobre as tentativas de uma política segregacionista nos Estados Unidos, Carnal diz o seguinte:

Leis de segregação racial haviam feito breve aparição durante a reconstrução, mas desapareceram até 1868. Ressurgiram no governo de Grant, a começar pelo Tennesse, em 1870: lá, os sulistas brancos promulgaram leis contra o casamento inter-racial. Cinco anos mais tarde, o Tennessee adotou a primeira Lei Jim Crow e o resto do sul o seguiu rapidamente. O termo 'Jim Crow', nascido de uma música popular, referia-se a toda lei (foram dezenas) que seguisse o princípio 'separados, mas iguais', estabelecendo afastamento entre negros e brancos nos trens, estações ferroviárias, cais, hotéis, barbearias, restaurantes, teatros, entre outros (CARNAL, 2007, P. 145).

De acordo com Morris e Burnett (2018), a ideologia da supremacia branca esteve presente na construção da sociedade americana, tomando força com o racismo de Jim Crow, sistema que criou leis que vigoraram, principalmente, no sul dos Estados Unidos, com as quais foram implementadas diversas medidas que deveriam ser colocadas em prática, como a separação entre negros e brancos nas instituições escolares, nos trens e nas repartições públicas. Em seguida, ocorreram diversos 
linchamentos e ainda enforcamentos de muitos negros utilizando a tática de pendurálos em árvores. Por serem considerados uma raça inferior semelhante aos chipanzés, deveriam permanecer no estado de inferioridade em relação aos demais indivíduos da sociedade, pois, segundo essa ideologia, esta era a vontade de Deus: que a pessoa negra se mantivesse em posição de sub-humanidade (MORRIS E BURNETT, 2018). Segundo os autores, essa ideologia ganhou corpo com a propagação da ciência branca disseminada no período do lluminismo, que apregoava o desenvolvimento intelectual do sujeito branco, levando a um estágio de superioridade humana. Nessa direção, a defesa da ciência branca e da ideologia da superioridade caminham lado a lado justificando a opressão racial (MORRIS E BURNETT, 2018).

Segundo Nascimento (2019), esse embate de condição de direito entre brancos e negros foi largamente discutido por Du Bois em seu livro "As almas do povo negro". Ali, ele faz um descortiçamento da situação vivida pela comunidade afroestadunidense, que lutava pela liberdade numa terra em que, embora já estivesse sido conquistada por eles, ainda se sentiam estrangeiros. Eles carregavam em seu interior um dualismo nacionalista envolvido pelo sentimento de ser americano e de ser negro, como descrito por Du Bois, que diz: "Duas almas, dois pensamentos, dois embates irreconciliáveis, dois ideais conflitantes, num corpo negro, impedido, apenas por um obstinado esforço, de bipartir-se" (DU BOIS, 1903, p. 39). Para os afroestadunidenses, o fato de serem reconhecidos como pessoas negras não thes causava nenhum constrangimento, pois tinham a consciência de que corria sangue negro em suas veias. Desejam, simplesmente, também conquistar o direito de serem cidadãos americanos, de não sofrer exclusão social, a ponto de thes serem negadas as oportunidades, de não verem as portas se abrirem para as circunstâncias que the eram favoráveis (DU BOIS, 1903, p. 39).

No entendimento de Nascimento (2019), Du Bois chama atenção para a situação do estado psicológico do indivíduo negro no percurso de sua vida, que vive sofrendo com a sensação de estar sempre sendo rejeitado pelos demais sujeitos. Cercados por esse sentimento de inferioridade, os negros americanos se consideravam um problema para a sociedade. Nascimento (2019) relata que Du Bois afirma que a problemática 
do sentimento de inferioridade por parte do negro começa na infância e o acompanha por toda a vida. Para dar sustentação a sua tese, ele faz o relato de uma experiência que se passou com ele mesmo. Tudo aconteceu quando, ainda na sua adolescência, teve contato com uma nova colega branca de classe que acabara de se mudar. $\mathrm{Na}$ troca de cartões entre os alunos na escola, a menina se recusou a receber o cartão dele. Foi então que Du Bois percebeu que era considerado diferente, havendo um enorme véu que o separava do mundo, o racismo (NASCIMENTO, 2019).

Conforme Morris e Burnett (2018), para Du Bois, existe uma linha de cor que sustenta a estrutura global da supremacia racial, que é amparada por um conjunto de forças ideológicas, políticas e econômicas. Para o autor, essa linha consiste numa barreira de relações entre as raças de homens mais claros e mais escuros, à beira da qual os homens se movem perigosamente. Os autores afirmam que, no pensamento de Du Bois, a estrutura social comandada pelo poder econômico do branco sobre os negros só seria superada se os negros conseguissem alcançar um alto posicionamento econômico, porém essa condição exigia a união de todos os negros com o objetivo de triunfar sobre a segregação racial, pois a fragmentação e o isolamento proporcionam a facilidade para a dominação. Nesse sentido, o foco principal do autor é combater esse tipo de segregação, que é posta de maneira semiconsciente ou explícita (MORRIS E BURNETT, 2018).

Segundo Moore (2007, p. 26), "os progressos alcançados na luta mundial contra o racismo sistêmico são modestos e frágeis." De acordo com o autor, podemos observar que a sociedade norte-americana tem sofrido um retrocesso em relação às conquistas adquiridas nas décadas 1960 e 1970, quando Martin Luther king e Malcolm X, como era chamado "Al hajjmalik Al-Shabazz", conquistaram o direito de voto para a comunidade negra, em 1965, por intermédio da Lei dos Direitos Civis de 1964. Os avanços acontecidos naquele período foram extraordinários, pois a segregação foi superada e as oportunidades de emprego, educação e moradia começaram a surgir para os negros. Além disso, muitos afro-americanos foram eleitos para os cargos de vereador e prefeito. Os retrocessos, claramente evidenciados, tornam-se testemunha 
do árduo e longo caminho que ainda teremos que trilhar rumo à superação da segregação racial (MOORE, 2007, p. 26).

\section{CONCEITOS E ANÁLISE DO DISCURSO ANTIRRACISTAS}

No contexto atual, é bastante recorrente o discurso do antirracismo na sociedade. Nas palavras de Fernandes (2007), quando ouvimos falar a palavra "discurso" logo nos vem à mente os mais eloquentes pronunciamentos políticos, contudo todas as formações discursivas estão sempre carregadas de formações ideológicas. Nesse sentido, é interessante que aconteça uma análise do discurso, que se caracteriza não prioritariamente pelo usa da língua no contexto político, mas no social, quando constatamos no dia a dia pessoas entrando em discussões e debates acerca de assuntos que estão em evidência (FERNADES, 2007). Sendo assim, o discurso sobre o antirracismo toma lugar no seio da sociedade, mas com suas variadas formas de sugestão e opiniões a respeito do assunto.

Para os autênticos defensores da causa negra, discursar sobre a situação da comunidade negra é lutar por justiça social. Para outros, o discurso antirracista é cercado do preconceito que o próprio negro tem contra si mesmo (FERNADES, 2007). Nessa direção, o discurso do mito da democracia racial é um instrumento de cunho ideológico construído por representantes intelectuais da camada social elitizada que buscam convencer a população de que brancos e não brancos são iguais (HASENBALG, 1979). A tentativa de convencer a raça negra de não realizar um levante contrário ao sistema de privilégio aos brancos tem por finalidade evitar o agregamento coletivo e a desmobilização de ações políticas que tenham condições de barrar o avanço da luta antirracista, isso ocorre porque "a eficácia da ideologia racial dominante manifesta-se na ausência de conflito racial aberto e na desmobilização política dos negros, fazendo com que os componentes racistas do sistema permaneçam incontestados, sem necessidade de recorrer a um alto grau de coerção" (HASENBALG, 1979, p. 246).

Segundo Schucman (2010), as investidas na tentativa de reprovar as lutas da identidade negra continuam sendo empregadas pela elite branca quando esta faz a 
narrativa de que brancos e negros desfrutam dos mesmos direitos e oportunidades. Em relação a essa declaração, Peter Fly (2005) diz que "o que continua em jogo, entretanto, é a distância entre discursos e práticas das relações raciais" (PETER FLY, 2005). Diante disso, o movimento negro mundial tenta desmistificar, por meio de seus intelectuais, a ideia de igualdade proclamada pela população não negra e desconstruir o mito da democracia racial.

Para Ribeiro (2020), a palavra segregação significa separação, divisão a fim de evitar contato, isolamento. De acordo com Leite (2020), o termo também pode ser utilizado no contexto de Estado, visando realizar uma separação entre os indivíduos ou grupos de pessoas que fazem parte de uma mesma sociedade, no entanto se apoderando de critérios étnicos e raciais. Vale explanar que a definição de raça, na sua categoria funcional, exige uma construção discursiva, histórica, social e, principalmente, política de forma mais ampla, cujo espaço limitado não nos permite fazer no momento. Para Guimarães (1999), "raça é uma forma de carisma ou estigma grupal baseada na crença de uma herança genética que define o valor moral, intelectual e psicológico de um indivíduo ou de um grupo." (GUIMARÃES, 1999, P.114). Já Sílvio Almeida (2018) diz que seu "significado sempre esteve de alguma forma ligado ao ato de estabelecer significações, primeiro, entre plantas e animais e, mais tarde, entre seres humanos." Almeida diz que "a noção de raça como referência e as distintas categorias de seres humanos é um fenômeno da modernidade." (ALMEIDA, 2018, p.19). O referido autor tem a preocupação de nos advertir que essa observação nos leva a compreender que o termo raça não é estático, mas aponta para um contexto histórico e cultural da humanidade, estando sempre ligado a interesses políticos e econômicos ladeados de conflitos de poder (ALMEIDA, 2018, p.19).

Conforme Fanon (1983, p. 44), "não se pode exigir impunemente que um homem seja contra os preconceitos do seu grupo. Todo o grupo colonialista é racista". Assim, a estruturação da sociedade sempre esteve ligada a ideologias de dominação do branco sobre o preto. Inclusive, a formação de poder econômico estruturado no capitalismo sempre foi o resultado de dominação colonialista. A tese do branqueamento, baseada na presunção da superioridade branca, revelou-se a acomodação ideal para o legado 
escravista (CAMARGO, 2010). Da Matta chama atenção para o fato de que "esses tipos de preconceito racial são inteiramente coerentes com as ideologias dominantes de cada uma dessas sociedades, estando diretamente relacionados com as formas escolhidas historicamente de recorte da realidade social". (DA MATTA, 2000, p. 81).

Segundo Cardoso (2011), a reinvindicação de caráter universal do povo negro, na busca de alcançar o reconhecimento étnico e racial, está diretamente relacionado ao interesse de ser reconhecido como pessoa, porém com um predicado específico, qual seja, de pessoa negra. Cardoso faz essa observação em decorrência da discussão que vem tratando a respeito do conceito de branquitude emergente nas relações sociais, fruto do movimento negro. Nas palavras de Cardoso, "a branquitude, ou identidade racial branca, se constrói e reconstrói histórica e socialmente ao receber influência de escala local e global. Não se trata de uma identidade racial homogênea e estática. A branquitude modifica-se no decorrer do tempo" (CARDOSO, 2011, p.1). De acordo com o autor, o branco sempre se considera uma pessoa de característica peculiar, sem considerar que é marcado por uma cor ou etnia, e está cercado de privilégios simbólicos que o coloca numa posição de poder. Ele conceitua, contudo, que ser branco vai além de ocupar o espaço de poder: "Significa a própria geografia existencial do poder", isso ocorre porque "a identidade branca é a estética, a corporeidade mais bela. Aquele que possui a história e a sua perspectiva" (CARDOSO, 2014, p.17).

Na reflexão de Munanga (2008), mesmo com a chegada do século XXI, diante de tantas transformações sociais e culturais, a sociedade ainda transporta em seus lombos o negativo saldo do racismo estruturado que esteve presente no período do século VIII a meante do século XIX. Corroborando com as ideias de Hall, Munanga (2008) afirma que a chegada do novo milênio consubstanciou uma nova forma de racismo, envolvido pelas diferenças culturais e identitárias. De acordo com Hall (2006), todo esse aparato de pensamento unificador de branqueamento está sofrendo grandes transformações, pois o "sujeito previamente vivido como tendo uma identidade unificada e estável, está se tornando fragmentado; composto não de uma única, mas de várias identidades" (HALL, 2006, P. 12). Nessa circunstância, toda 
ordem pigmentocrática de dominação, que difunde o preconceito racial e dissemina de maneira aguda a desigualdade social, enfrenta a resistência do sujeito "pósmoderno," celebra a desconstrução do formato de sociedade unificada. "A consciência política reivindicativa das vítimas do racismo nas sociedades contemporâneas está cada vez mais crescente" (MUNANGA, 2008, p. 16).

\section{POR FAVOR, NÃO CONSIGO RESPIRAR; SUFOCADO POR UM JOELHO}

O episódio que aconteceu no dia 25 de maio de 2020, na cidade americana de Minneapolis, pode ser caracterizado como um ato racista. $O$ fato mencionado diz respeito à morte de George Floyd, um homem negro, de 46 anos de idade, que foi estupidamente assassinado por um policial branco sob a justificativa de ter passado uma nota falsa de vinte dólares no supermercado CupFoods. O funcionário do supermercado acreditava que a nota que Floyd havia passado para realizar o pagamento de um maço de cigarros era falsificada, por isso chamou a polícia. Mesmo Floyd não reagindo e não entendendo o que realmente estava acontecendo, foi algemado e torturado, por um período de aproximadamente oito minutos e meio. Desde que se mudara de Houston, sua cidade natal no Texas, Floyd morava na cidade de Minneapolis, e trabalhava como segurança, sempre foi considerado um cidadão pacato por todos. Havia sido demitido do último trabalho recentemente, por consequência da crise econômica instaurada pela pandemia da Covid-19.

Matéria vinculada no portal de notícias G1, de 30 de maio de 2020, afirma que há uma longa história de segregação e conflito racial em Minneapolis. De acordo com historiadores, Minneapolis é uma cidade onde a disparidade racial é extremamente grande, sendo considerada a quarta pior para os negros morarem. É extremamente segregada, e os negros que ali residem são proibidos de se mudarem para outras áreas. A segregação é tão extrema que durante décadas perdurou a lei que proibia os negros de possuírem propriedades, sendo permitido somente para pessoas brancas. Essas leis de restringência para os negros foram proibidas em 1968, no entanto seus 
efeitos ainda estão presentes em Minneapolis até os dias de hoje (PORTAL DE NOTÍCIAS, de 30 de maio de 2020).

Na época, o vice-presidente americano, Joe Biden, lamentou a morte de George Floyd e disse que, "este não é um incidente isolado, mas que faz parte de um ciclo sistemático de injustiça que ainda persiste nos Estados Unidos." Muitas personalidades do mundo artístico, político, esportivo, jornalístico e da sociedade em geral se manifestaram contra a violência racial nos Estados Unidos e no mundo. Segundo Quintiere (2020), a violência contra negros é bastante frequente, não sendo nenhuma novidade. De acordo com o autor, o ato de insanidade cometido pela polícia contra George Floyd trouxe à baila questões complexas sobre a história de racismo nos Estados Unidos. Esse episódio fertilizou na lembrança dos americanos outros casos de violência policial, ocorridos em anos anteriores, como o triste episódio de violência contra Rodney King, em 1991, na cidade de Los Angeles, quando quatro policiais o espancaram, de maneira animalesca, com chutes e pontapés, com mais de cinquenta pancadas. Ainda pior que o cruel espancamento foi a absorção dos agressores que ficaram impunes. Essa ausência de punição gerou uma grande revolta por todos os lugares dos Estados Unidos na época.

Outro episódio que merece ser lembrado diz respeito ao caso ocorrido no dia 26 de fevereiro de 2012, na cidade da Flórida, quando o jovem Trayvon Martin foi baleado e morto por um segurança armado que fazia ronda nos bairros da cidade, fato que fez brotar o movimento "Black lives Matter" (em português: vidas negras importam). Segundo Rodrigues (2021), o jovem tinha apenas 17 anos de idade e seguia para a casa do seu pai, em Sanford, quando foi abordado e morto. É importante salientar que Trayvon não estava armado, nem era suspeito de qualquer irregularidade ou infração, mas o bairro em que Trayvon se encontrava naquele dia tinha um histórico de ocorrência de muitos assaltos à mão armada. Na noite que Trayvon foi morto, estava chovendo, e quando o jovem foi visto pelo segurança andando na rua foi considerado como um dos suspeitos de ser assaltante. George Zimmerman, o segurança, quando o avistou não pensou duas vezes e o baleou, com a desculpa de pensar que se tratava de um assaltante. Como no caso de Rodney King, agredido publicamente por policiais, 
que também ficou impune, e, mais uma vez, gerou manifestações em diversos lugares pedindo que George Zimmerman fosse acusado formalmente pela morte do garoto Trayvon.

De acordo com o jornal da British Broadcasting Corporation (BBC News), naquela época, o então presidente dos Estados Unidos, Barak Obama, disse algo extraordinário. O presidente se manifestou dizendo: "Se eu tivesse um filho, se pareceria com Trayvon. Creio que todos nós devemos fazer um exame de consciência para averiguar como algo assim pode ter acontecido e isso passa por examinar as leis e o contexto em que isso aconteceu." (BBC NEWS, 23 março 2012).

O contexto histórico dos Estados Unidos mostra uma desvalorização do homem negro, que, no século VIII, chegavam em grande número, advindos do tráfego negreiro, para serem utilizados nos serviços de cultivo de tabaco, algodão, milho e arroz. Esses negros trabalhavam de sol a sol, nas piores condições, chegando a passarem até dezessete horas trabalhando ininterruptamente, tendo apenas um pequeno intervalo de tempo para realizarem a refeição do almoço. Mesmo sendo eles os principais responsáveis pelo crescimento e desenvolvimento econômico do país, principalmente na região sul, sempre estiveram em desvantagem econômica, social e política (CARNAL, 2007).

A morte de George Floyd foi filmada por pessoas que passavam pelo local e solicitaram ao agente de segurança que retirasse o joelho do pescoço de Floyd, no entanto, um dos militares, Derek Chauvin, não deu atenção aos apelos da população. Floyd também implorava por sua vida e clamava dizendo "por favor, não consigo respirar, não me mate". De acordo com Pâmela Malva (2020), George Floyd foi um ícone da luta antirracista, um pai amável, um esposo dedicado e um guerreiro em busca de novas oportunidades na vida profissional. De acordo com os amigos, George apresentava gentileza e tranquilidade. Eles o chamavam de Big Floyd (grande Floyd). Pâmela relata que ele sempre foi uma "pessoa carinhosa, com um coração igual ou superior à sua estatura física de quase dois metros de altura." Ainda disse que, apesar de todas as dificuldades e de ter sido acusado, em 2007, de assalto à mão armada, Floyd não era nem um pouco a favor da violência. Ele deixava isso claro nas suas 
postagens nas redes sociais. Em um de seus últimos posts, George foi categórico quanto à violência armada dizendo: "Nossa geração jovem está claramente perdida." (MALVA, 2020).

Quincy, o filho mais velho de Floyd, disse: "Quero tentar justiça para meu pai. Nenhum homem ou mulher deveria perder o pai assim." Já a pequena Gianna, de 6 anos de idade, gritou para o mundo inteiro ouvir: "Papai mudou o mundo." A mãe de Gianna disse que a filha não tinha noção do que realmente estava acontecendo, e falou essa expressão porque ouvia as pessoas gritarem a todo tempo o nome de seu papai. (CARTA CAPITAL, 2020). As manifestações que levaram milhares de pessoas às ruas dos Estados Unidos após a morte de George Floyd são uma demonstração de que a sociedade não tolera mais o racismo estrutural, ainda existente no contexto atual. Combater o racismo significa lutar contra as ideologias de superioridade do branco sobre o negro, não lutar contra os indivíduos.

A ideologia de superioridade de um sujeito branco, e vestindo uma farda de agente de segurança do Estado, foi descarregada sobre um sujeito desarmado, que não oferecia nenhum risco de morte aos policiais, visto que já estava imobilizado pelas nefastas algemas. A morte de Floyd, efetivamente, trata-se de um momento ímpar na história, considerando a dimensão do problema e o impacto causado internacionalmente. Assim sendo, perguntamos: Quais instrumentos são indispensáveis para fomentar políticas de igualdade racial de forma satisfatória? Como podemos fugir desse fantasma que aterroriza a humanidade? Qual a solução para sair desse atoleiro brutal? Para Barbara Bergmann (1996), Sabrina Moehlecke (2002) e outros estudiosos do assunto, a saída pode estar na prática de ações afirmativas. É sobre isto que falaremos a seguir.

\section{AÇÕES AFIRMATIVAS: UMA PROPOSTA DE SUPERAÇÃO DO RACISMO E DAS DESIGUALDADES}

A discriminação racial na qual está mergulhada a comunidade negra afasta dela qualquer possibilidade de galgar posição de destaque na sociedade. Os elevados índices de violência contra essa comunidade são a face mais feroz dessa situação. 
"O racismo que se encontra na raiz dos desarranjos sociais extremos vivenciados em praticamente todos os países do mundo, tornando-o a última fronteira do ódio no planeta." (MOORE, 2007, p. 279). Está definitivamente claro que o racismo é uma forma específica do ódio. Aliás, um ódio dirigido peculiarmente contra uma parte da humanidade, que fica excluído dos recursos essenciais em termo de acesso à "educação, aos serviços públicos, aos serviços sociais, ao poder político, ao capital de financiamento, às oportunidades de emprego, às estruturas de laser, e até ao direito de ser tratado equitativamente pelos tribunais de justiça e as forças incumbidas da manutenção da paz." (MOORE, 2007, p. 279).

Diante dessa problemática, de negação de direitos, exclusão, bloqueio e violência contra os não brancos, surge uma indagação: Quais instrumentos políticos são necessários para garantir o direito das igualdades de raça de forma satisfatória? Antes de dar resposta a essa indagação, consideramos importante fazer menção ao processo histórico da legislação no percurso da percepção de igualdade de direitos para todos. De acordo com a revista Âmbito Jurídico, historicamente, a proposta de desconstruir a desigualdade social, envolvendo a população negra, perpassa pela legislação jurídica, que vem, mundialmente e há anos, trabalhando no sentido de assegurar os direitos legislativos apontados pelas constituições e os direitos humanos. (REVISTA JURÍDICA, 2015).

Em busca de respostas para as questões de desequilíbrio racial entre brancos e não brancos, foi elaborado, em 1968, o primeiro registro de implementação de ações afirmativas no Brasil. Nesse primeiro documento, o principal propósito foi construir e promulgar uma lei, através de técnicos do Ministério Público do Trabalho, que obrigasse as empresas, mais especificamente as privadas a contratarem e manterem em seu quadro de trabalho uma porcentagem de no mínimo 10 a $20 \%$ de pessoas negras. Essa proposta tinha o objetivo de amenizar a problemática da discriminação racial referente ao mercado de trabalho, que valorizava mais o sujeito branco em detrimento do sujeito negro. Mas, surpreendentemente ou não, essa lei não chegou nem a sair do papel, e as exclusões sociais trabalhistas continuaram a existir (REVISTA JURÍDICA, 2015). 
Passados quinze anos da primeira tentativa, já em 1983, a discussão sobre a inclusão dos negros no mercado de trabalho volta ao palco, dessa vez por intermédio do deputado federal Abdias Nascimento, que apresentou a Lei n.ำ 1.332. Nessa lei, mais uma vez, fora proposta a reserva de $20 \%$, tanto para as mulheres quanto para os negros, na seleção de candidatos para o serviço público. Tudo parecia está dando certo para a reversão da discriminação racial, contudo, mais uma vez, o projeto não foi aprovado pelo Congresso, e tudo voltou à estaca zero. Faz-se necessário dizer que as solicitações permaneceram, por meio de movimentos e mobilizações, visando encontrar soluções para a problemática da violência contra o negro. (REVISTA JURÍDICA, 2015).

Sabrina Moehlecke (2002) apresenta o sistema de ações afirmativas como uma das alternativas capazes de minimizar o problema da discriminação e exclusão racial ainda presente no contexto vigente. De acordo com a autora, o termo "ações afirmativas" teve origem nos Estados Unidos, com a luta pela democratização interna, capitaneada por Martin Luther King nos anos 60, pretendendo, principalmente, garantir o direito aos negros de votar e serem votados. O movimento tinha a intenção de concretizar o direito de igualdades para todos. É nesse cenário que surge a proposição de uma ação afirmativa, que tinha como pretensão conseguir do Estado uma postura política que melhorasse as condições da população negra (MOEHLECKE, 2002). Logo, a ideia de ação afirmativa se estendeu por várias partes do mundo. "Experiências semelhantes ocorreram em vários países da Europa Ocidental, na Índia, Malásia, Austrália, Canadá, Nigéria, África do Sul, Argentina, Cuba, dentre outros." (MOEHLECKE, 2002).

A expressão ação afirmativa aparece com diversas interpretações entre os estudiosos do assunto. Para Barbara Bergmann (1996), o termo tem sentido amplo, e significa planejar e executar ações no sentido de possibilitar a representatividade de certos tipos de pessoas, que permanecem submetidas aos caprichos daqueles que se consideram superiores. Para a autora, a ação afirmativa é uma entidade que luta pelo rompimento da tradição, que sempre eleva e promove somente pessoas brancas, por serem consideradas mais capacitadas para o exercício de funções e atividades que 
os negros. Para ela, "ações afirmativas podem ser um programa formal e escrito, um plano envolvendo múltiplas partes e com funcionários dele encarregados, ou pode ser a atividade de um empresário que consultou sua consciência e decidiu fazer as coisas de uma maneira diferente." (BERGMANN, 1996, p.7).

Para Guimarães (1997), as ações afirmativas estão diretamente ligadas ao processo democrático por meio do qual as sociedades inferiorizadas têm a oportunidade de participar do princípio da igualdade social. Essas ações estariam responsáveis em "promover privilégios de acesso a meios fundamentais, educação e emprego, principalmente a minorias étnicas, raciais ou sexuais que, de outro modo, estariam excluídas desses direitos, total ou parcialmente." (GUIMARÃES, 1997, p. 233). Já Santos (1999) é mais ousado e acredita que essas ações são instrumentos com capacidade suficiente de excluir as desigualdades sociais amontoadas historicamente, tendo a condição de oportunizar igualdades de direitos para todos, inclusive os negros. Com essa probabilidade, seria possível acontecer uma compensação de perdas provocadas pela discriminação durante a história. (SANTOS, 2005, p. 25).

\section{CONSIDERAÇÕES FINAIS}

Podemos observar que o sistema em seu conjunto, como um todo, vem falhando no cuidado e respeito às diferenças raciais. Podemos observar que ainda existe uma fragilidade enorme em relação às garantias de direitos adquiridos. $O$ povo negro e 0 povo indígena sofrem ainda com a exclusão social. Sendo assim, como podemos observar, esse não é um problema somente dos Estados Unidos, mas, também do mundo todo. Como exposto neste trabalho, a segregação, a exclusão e a desigualdade decorrente da discriminação racial existem, e devem ser rechaçadas de nosso sistema, pois impedem as nações, e a própria humanidade, de evoluir. Para que isso realmente ocorra, devemos lançar mão das medidas tão benéficas das ações afirmativas, que podem ser traduzidas pela célebre frase de nosso ilustre jurista, Rui Barbosa, que afirmava que "devemos tratar os desiguais com desigualdade". Essa é a verdadeira expressão de igualdade. 
Neste texto tivemos o cuidado de nos determos peculiarmente no caso de George Floyd, americano morto no dia 25 de maio de 2020, em Minneopolis, nos Estados Unidos da América, mas poderíamos apresentar um diverso número de casos ocorridos pelo mundo. Não poderíamos, porém, fazer estas considerações finais sem mencionar o caso do, também americano, Eric Garner, outro negro que, como Floyd, sofreu violência policial e morreu também asfixiado, em Nova lorque, no ano de 2014. A mesma frase que Floyd disse nos seus últimos momentos de vida ("não consigo respirar") foi repetida por Eric Garner, repetida por onze vezes. Todos esses aspectos revelam um espaçoso campo de batalha e, de certa forma, uma batalha desigual, pois está fixada entre indivíduos revestidos de poder, político e jurídico, contrassujeitos considerados inferiores e excluídos, os negros.

Toda essa problemática se apresenta com um único nome: violência. Para Chauí (1998), a violência está em tudo aquilo que procede com o rigor da força para ir de encontro à natureza de alguém. Diz mais: é toda prática de autoritarismo que reprime a liberdade de alguém contra a sua vontade; é, ainda, um ato de violação de direitos de igualdades; é toda forma de ação que um grupo ou sociedade coloca como sendo melhor que a do outro, ou seja, etnocentrismo puro. Para que o racismo seja combatido, é preciso que o Estado reconheça a existência real das raças.

\section{REFERÊNCIAS}

ALMEIDA, Silvio Luiz de. 0 que é racismo estrutural? Belo horizonte, letramento, 2018.

BERGMANN, Barbara. Em defesa da ação educativa. New York: Basic Books, 1996.

BRITISH BROADCASTING CORPORATION (BBC NEWS,). Caso George Floyd: 11 mortes que provocaram protestos contra a brutalidade policial nos EUA. Disponível em: https://www.bbc.com; acessado em 15 de jun. de 2020.

CAMARGO, Oswaldo. O negro escrito. São Paulo: disponível em: www.letras. ufmg.br. Acessado em: 12 de jun. de 2020. Secretaria de estado da cultura, 1987. 
CARDOSO, Lourenço. O branco ante a rebeldia do desejo: um estudo sobre a branquitude no Brasil; Tese de Doutorado, Araraquara 2014.

CARTA CAPITAL. Prefeito de Minneapolis diz a Trump: "Fraqueza é culpar os outros em tempos de crise." Disponível em https://www.cartacapital.com.br/mundo/prefeito-de-minneapolis-diz-a-trumpfraqueza-e-culpar-os-outros-em-tempos-de-crise/. Acessado em: 16 de jun. de 2020.

CHAUÍ, Marilena. Ensaio Ética e violência. Revista Teoria e Debate, ano 11, n. 39, 1998.

DA MATTA, Roberto. Relativizando: uma introdução à antropologia social. 6. ed. Rio de Janeiro: Rocco, 2000.

DU BOIS, W. E. B. As Almas do Povo Negro, disponível em: https://afrocentricidade.files.wordpress.com/2016/04/as-almas-do-povo-negro-w-e-bdu-bois.pdf: acessado em: 05 de julho de 2021.

ERIC Garner; Policial acusado de asfixiar afro-americano Eric Garner não será denunciado. 17/07/2019. Disponível em: https://noticias.uol.com.br/ Acessado em: 12 de jun. de 2020.

ESTADÃO. Entenda o caso do adolescente negro assassinado na florida. Disponível em: https://internacional.estadao.com.br/noticias/geral,entenda-o-caso-doadolescente-negro-assassinado-na-florida,852521 https:// acessado em 20 de junho de 200 .

FANON, Frantz. Pele negra, máscaras brancas. Rio de Janeiro: Editora Fator. 1983.

FERNANDES, Cleudemar Alves. (Re)Tratos Discursivos do Sem-Terra. Uberlândia: EDUFU, 2007.

FLORES, Tarsila. Cenas de um Genocídio: homicídios de jovens negros no Brasil e a ação de representantes do Estado; Brasília/DF 2017. 
FRY Peter. Política, Nacionalidade e o Significado de 'Raça' no Brasil. Em A persistência da raça: ensaios antropológicos sobre o Brasil e a África austral. Rio de Janeiro: Civilização Brasileira. 2005.

GUIMARÃES, Antônio Sérgio Alfredo. A Desigualdade que anula a desigualdade: notas sobre a ação afirmativa no Brasil. In: SOUZA, J. (org.). Multiculturalismo e racismo: uma comparação Brasil e Estados Unidos. Brasília: Paralelo 15, 1997, p.233-242.

GUIMARÃES, Antônio Sérgio Alfredo. Combatendo o racismo: Brasil, África do Sul e Estados Unidos. Revista Brasileira de Ciências Sociais - vol. 14 no 39. 1999.

HALL, Stuart. A identidade cultural na pós-modernidade, 11ª Edição. São Paulo. 2006

HASENBALG, Carlos. Discriminação e desigualdades raciais no Brasil. Rio de Janeiro, Graal. 1979.

KARNAL, Leandro. et al. História dos Estados Unidos: das origens ao século XXI. São Paulo: Contexto, 2011.

LEITE, Gisele; Considerações sobre a segregação racial nos estados. Disponível em: https://www.geledes.org.br/Acessado em: 11 de jun. de 2020.

MBEMBE, Achille. Políticas da inimizade. Lisboa: Antígona. 2017.

MBEMBE, Achille. A Crítica da razão negra. São Paulo: n-1 edições, 2018.

MOEHLECKE Sabrina: ção afirmativa: história e debates no Brasil. Cadernos de pesquisa, Cad. Pesqui. №. 117 São Paulo Nov. 2002; acessado em 16 de jun. 2020.

MOEHLECKE, Sabrina. Propostas de ações afirmativas para o acesso da população negra ao ensino superior no Brasil: experiências e debates. In: Programa a cor da Bahia. A Educação e os afro-brasileiros. Salvador: UFBA; Novos Toques, 2000, p.167-181. 
MOORE, Carlos. Racismo e sociedade: novas bases epistemológicas para entender o racismo. Belo Horizonte: Mazza Edições, 2007.

MORRIS, Aldon, e BURNETT Annahid. Du Bois: no centro da ciência, do movimento dos direitos civis, ao movimento Black Lives Matter. Revista Interlegere, Natal, v. 1, n. 23, jul./dez, 2018.

MOTA, Lúcio Tadeu. O Instituto Histórico e Geográfico Brasileiro e as propostas de integração das comunidades indígenas no Estado Nacional. Diálogos, Maringá: Universidade Estadual de Maringá - UEM, Departamento de História - DHI, v. 2, n. 1, p. 149-175, 1998. Disponível em: https://biblioteca.ibge.gov.br/. Acesso em: 13 de jun. 2020.

MUNANGA, kabengele. Superando o racismo na escola. 2. Ed. Rev. Brasília: MEC, 2005.

NASCIMENTO, Abdias. O genocídio do negro brasileiro, processo de um racismo mascarado. Rio de Janeiro: Editora Paz e Terra, 1978.

NASCIMENTO, Ana Carolina Santos. Du Bois: uma leitura / Disponível em: https://www.maxwell.vrac.puc-rio.br/49405/49405.PDF, Dissertação de mestrado, orientadora: Maria Alice Rezende de Carvalho. 2019.

PAMELA Malta, Quem era George Floyd? 03 de junho de 2020, disponível em: as aventuras na história.UOL notícias. Acessado em 15 de jun. de 2020.

PORTAL DE NOTICIAS G1, A longa história de segregação e conflito racial em Minneapolis, onde George Floyd foi morto pela polícia. G1. 30 de maio de 2020. Disponível em; g1. Globo.com > mundo > noticia > acessado em: 15 de jun.2020.

QUINTIERE Victor Minervino; O racismo estrutural e a violência policial nos Estados Unidos: análise do caso George Floyd. Revista Consultor jurídico, 6 de jun. De 2020; acessado em 14 de jun. De 2020. 
REVISTA JURÍDICA, Ações afirmativas à luz dos direitos humanos: uma premente busca à igualdade de gêneros. Disponível em: https://ambitojuridico.com.br/01/09/2015; acessado em: 15 de jun. de 2020.

REVISTA JURÍDICA, Breve análise sobre a ação afirmativa. Disponível em; https://ambitojuridico.com.br/28/02/2005; acessado em, 10 de jun. de 2020.

RIBEIRO, Paulo Silvino. "Segregação racial"; Brasil escola. Disponível em: https://brasilescola. uol.com. br/sociologia/segregacao-racial.htm. Acesso em 01 de junho de 2020.

ROCHA, Alexandre Pereira; George Floyd: esse não é só um caso policial. Outras palavras. Net, publicado em 04 de junho de 2020. Acessado em 12 de jun. 2020.

RODRIGUES, Vera. Vidas negras importam: o que dizemos nós mulheres negras ativistas, intelectuais e artistas. Tessituras | Revista de Antropologia e Arqueologia | ISSN: 2318-9576, v9 | n1 | pelotas | rs. jan-jun 2021.

SANTOS, Sales. Ações afirmativas e combate ao racismo nas Américas. Brasília: MEC/UNESCO, 2005.

SCHUCMAN, Lia Vainer, Racismo e Antirracismo: a categoria raça em questão. Revista Psicologia Política. vol. 10. № 19. pp. 41-55. jan. - jun. 2010.

Enviado: Dezembro, 2020.

Aprovado: Dezembro, 2021. 